\title{
PERCEPÇÃO DOS PROFISSIONAIS DE EDUCAÇÃO SOBRE 0 ENVELHECIMENTO DA PESSOA COM DEFIIIENCIIA INTELECTUAL
}

Karina Silveira de Almeida Hammerschmidt; Departamento de Enfermagem da Universidade Federal do Paraná (UFPR); ksalmeidah@ufpr.br;

Lisiane Capanema Silva Bonatelli; Departamento de Enfermagem da Universidade Federal de Santa Catarina (UFSC); licapanema@gmail.com;

Soraia Dornelles Schoeller; Departamento de Enfermagem da Universidade Federal de Santa Catarina

(UFSC); soraia.dornelles@ufsc.br;

Juliana Balbinot Reis Girondi; Departamento de Enfermagem da Universidade Federal de Santa Catarina; juliana.balbinot@ufsc.br;

Fernanda Rosa de Oliveira Pires. Departamento de Enfermagem Universidade Federal de Sant Catarina; nandadode@hotmail.com;

Giordanna Nayara Chagas e Silva; Departamento de Enfermagem da Universidade Federal do Paraná (UFPR); giordanna@ufpr.br;

Susanne Elero Betiolli; Departamento de Enfermagem da Universidade Federal do Paraná (UFPR); susanne@ufpr.br

\section{RESUMO}

Introdução: A evolução do processo de envelhecimento acelerado aflora a necessidade de considerar aspectos multidimensionais específicos para a avaliação da pessoa com deficiência. Objetivo: Apresentar a percepção dos profissionais da educação sobre o processo de envelhecimento da pessoa com deficiência intelectual. Método: Trata-se de pesquisa qualitativa, desenvolvida com 17 profissionais da educação, no período de maio a junho de 2020. Para coleta de dados foi utilizada entrevista gravadas e questionário estruturado, com uso da ferramenta eletrônica do Google Forms e Microsoft Teams. A análise dos dados foi realizada conforme Metodologia do Discurso do Sujeito Coletivo, com ideias centrais e correspondentes expressões-chave, agrupadas conforme a sua semelhança. Resultados: Os resultados evidenciam que as ideias centrais: 1) Envelhecimento da pessoa com deficiência intelectual é esperado, porém precoce; 2) Compreensão do processo de envelhecimento da pessoa com deficiência intelectual; 3) Estereótipos, preconceitos e estigmas vinculados ao idoso com deficiência intelectual, destaca-se o discurso relacionado aos preconceitos da velhice e infantilização do idoso; 4) Comprometimento das funções cognitivas no envelhecimento com deficiência intelectual; 5) Limitações e incapacidades dos idosos com deficiência intelectual exigem cuidado e apoio; 6) Dificuldades na comunicação dos idosos com deficiência intelectual. Conclusão: Faz-se necessário dar ênfase à pessoa e não somente a sua deficiência, assim como priorizar a participação plena e efetiva na sociedade; aprofundar informações e conhecimentos para a promoção da dignidade humana; e qualificar as ações para os idosos com deficiência intelectual, com ênfase nos dados de percepção dos profissionais da educação.

Palavras-chave: Idosos; Envelhecimento; Deficiência; Saúde; Educação. 